\title{
Revista Brasileira de História da Medicina, pioneira da historiografia médica*
}

\author{
Revista Brasileira de História da Medicina, a pioneer \\ in medical historiography
}

Amanda Mendonça

Estudante de ciências sociais, Rua Dionísio, n. 119

Penha - 21070-170

Rio de Janeiro - RJ

amandamendonca_rj@yahoo.com.br

Gabriel Baptista Nicolini

Estudante de história,

Rua Conselheiro Venha, n. 25

apto. 202

Tijuca - 20550-090

Rio de Janeiro - RJ

gbnicolini@bol.com.br
MENDONÇA, Amanda; NICOLINI, Gabriel Baptista. Revista Brasileira de História da Medicina, pioneira da historiografia médica.

História, Ciências, Saúde - Manguinhos,

Rio de Janeiro, v.14, n.1, p.269-284, jan.-mar. 2007.

Apresenta as características gerais da Revista Brasileira de História da Medicina, que fez aflorar o campo da história da medicina no Brasil ao estimular a produção bibliográfica nessa área. A análise tem por propósito contribuir para ampliar a pesquisa em história da medicina e da ciência. A partir da descrição dos aspectos editoriais do periódico, pode-se ter uma idéia de como se organizava aquele campo entre os anos 1940 e 1960. A revista permite, ainda, mapear os congressos que visavam o intercâmbio entre médicos historiadores brasileiros e estrangeiros.

PALAVRAS-CHAVE: Revista Brasileira de História da Medicina; periódicos científicos; história da medicina no Brasil; pesquisa histórica.

MENDONÇA, Amanda; NICOLINI, Gabriel Baptista.

Revista Brasileira de História da Medicina, a pioneer in medical historiography .

História, Ciências, Saúde - Manguinhos,

Rio de Janeiro, v.14, n.1, p.269-284, Jan.-Mar. 2007.

I(It?This?) presents the general characteristics of the Revista Brasileira de História da Medicina, which contributed for the emergence of the field of medicine history in Brazil by inciting bibliographic production on the subject. The purpose of our analysis is to foster research on the history of medicine and of the sciences. From the description of the editorial aspects of the journal one can have an idea of how the research field was organized between 1940 and 1960. The periodical also allows for an overview of the exchange occurring between Brazilian and foreign historian physicians at that time.

KEYWORDS: Revista Brasileira de História da Medicina, scientific journals, history of medicine in Brazil, historical research. 
* Este artigo é resultado parcial do projeto de pesquisa de iniciação científica junto ao Programa Institucional de Bolsas de Iniciação Científica (Pibic). No projeto, sob a orientação de Jaime Benchimol e coorientação de Roberta Cardoso Cerqueira e Ruth B. Martins, participamos das várias etapas da pesquisa intitulada "A história da história da medicina no Brasil. Da Revista Brasileira de História da Medicina a História, Ciências, Saúde - Manguinhos". Gabriel B. Nicolini integrou a equipe desse projeto entre agosto de 2003 e julho de 2004; Amanda Mendonça, desde agosto de 2004.

Agradecemos a valiosa colaboração do doutor Joffre Marcondes Resende, membro fundador da Sociedade Brasileira de História da Medicina.
E ste artigo apresenta aspectos da Revista Brasileira de História da Medicina, fundada na década de 1940, e de suas instituições fundadoras, a Federação Nacional de História da Medicina e Ciências Afins e o Instituto Brasileiro de História da Medicina. Todos parecem constituir relevantes objetos de análise, no que concerne à história da medicina e ao periodismo científico do campo médico.

A Federação Nacional de História da Medicina e Ciências Afins e o Instituto Brasileiro de História da Medicina foram criados logo após a Segunda Guerra Mundial, ao que parece simultaneamente, sobressaindo entre os protagonistas desse projeto ambicioso e expansionista o médico Ivolino de Vasconcellos (5.6.1917-25.1.1995). Depois de graduar-se doutor em medicina pela Faculdade Fluminense de Medicina, em 1939, Vasconcellos doutorou-se em direito pela Faculdade de Direito do Rio de Janeiro, dez anos depois. Além de fundar e presidir, até seu falecimento, o Instituto Brasileiro de História da Medicina, foi membro de institutos de história da medicina de diversos estados. Também foi responsável pela fundação das Revista Médica Brasileira e Revista Brasileira de História da Medicina. Autor de mais de duzentos artigos em periódicos nacionais e estrangeiros, sobre medicina clínica, história da medicina e medicina social, tornou-se personalidade preponderante do movimento que colocou o Brasil no mapa internacional dos estudos de história da medicina. ${ }^{1} \mathrm{Em} 1947$, propôs que se incluísse essa disciplina no currículo da Faculdade Nacional de Medicina da Universidade do Brasil, da qual era docente. Vasconcellos chegou a ministrar um curso de extensão nessa faculdade, cuja aula inaugural, em 18 de março de 1947, versou sobre "A evolução dos estudos de história da medicina no Brasil".

A instituição pioneira nesse domínio parece ter sido a Sociedade Paulista de História da Medicina, sobre a qual temos poucos dados. Foi criada em 1940 e continuava operante na década seguinte, pois em novembro de 1950 Eduardo Vaz ali proferiu conferência sobre Vital Brazil (Vaz, nov. 1950), poucos dias antes da morte do cientista. Oito anos depois, o médico Alceu Maynard Araújo obteria o primeiro prêmio e a medalha de ouro no Concurso Arnaldo Vieira de Carvalho, promovido pela Sociedade. Consta ainda que, em 1959, a Sociedade Paulista de História da Medicina laureou, com esse mesmo prêmio, Siphilis - moléstia e termo - através da história, livro da autoria de Afrânio do Amaral.

Fundado em 30 de novembro de 1945, o Instituto Brasileiro de História da Medicina foi a sede ${ }^{2}$ da Federação Nacional de História da Medicina e Ciências Afins, formada por outros institutos espalhados pelo país. O Instituto Baiano de História da Medicina foi inaugurado a 11 de junho de 1947, tendo como presidente Eduardo de Sá Oliveira. Na mesma época, surgiram o Instituto Sul-riograndense de História da Medicina, com ativa participação de Tasso 
Vieira de Faria e, um pouco depois, os institutos paraibano e paranaense de história da medicina, o primeiro em João Pessoa ${ }^{3}$ e o segundo inaugurado em 14 de setembro de 1951 em solenidade em Curitiba, na Universidade do Paraná.

A Revista Brasileira de História da Medicina, órgão oficial Instituto Brasileiro de História da Medicina e da Federação Nacional de História da Medicina, foi criada em 30 de novembro de 1949. Destinada às "classes médicas e afins", foi trimestral até 1956, mensal até 1958, bimestral até 1963, havendo, por fim, somente uma edição relativa ao biênio 1968-1970.

As primeiras produções relativas à história da medicina elaboradas no Brasil foram atividades complementares ao trabalho dos médicos e abordavam basicamente biografias, instituições ou eventos científicos. Artigos publicados por Ivolino de Vasconcellos na revista que dirigia foram reunidos, em 1964, no livro intitulado Asclépio historiador. Ordival Cassiano Gomes, secretário-geral do Instituto Brasileiro de História da Medicina, é autor de um estudo sobre o pai de Rui Barbosa, o médico João José Barbosa de Oliveira (Gomes, 1949) e sobre Manuel Victorino Pereira, médico e cirurgião que foi vice-presidente da República no governo de Prudente de Morais. Publicou ainda dois trabalhos sobre a medicina quinhentista e seiscentista (Gomes, 1953, 1974). Eduardo de Sá Oliveira, ao se tornar presidente do Instituo Baiano de História da Medicina, havia já publicado Memória histórica da Faculdade de Medicina da Bahia: concernente ao ano de 1942 (Oliveira, 1992). Tasso Vieira de Faria, do Instituto Sul-rio-grandense de História da Medicina, participou também da instituição de sua especialidade, a obstetrícia, naquela capital. Proferiu a conferência "Os primórdios das atividades associativas em ginecologia e obstetrícia" em 20 de março de 1947, no auditório da Maternidade Mário Totta, da Santa Casa. Em 28 de maio do ano seguinte, participou da fundação da Seção de Ginecologia e Obstetrícia da Sociedade de Medicina de Porto Alegre, assumindo o cargo de secretário-geral da Sociedade de Ginecologia e Obstetrícia do Rio Grande do Sul, em 28 de setembro de 1949. ${ }^{4}$ O presidente do Instituto Paranaense de História da Medicina, o médico curitibano Carlos Stellfeld, além de exercer a cátedra de botânica na Universidade do Paraná, era membro da Academia Paranaense de Letras e chegou a dar nome a uma praça daquela capital. Homenagem do mesmo porte recebeu o vice-presidente da entidade, Júlio Estrella Moreira, cujo nome foi dado a uma escola municipal e à galeria subterrânea para pedestres, construída em 1976 no centro de Curitiba.

O primeiro número da Revista Brasileira de História da Medicina, publicado em 1949, era visto como um 'experimento' por seus editores, mas conseguiu atrair a atenção de importantes personalidades dos estudos sobre história da medicina. 
Desde o início, contou com colaboradores do Brasil e de outros países. Foi muito promissora a acolhida do porta-voz do Instituto Brasileiro de História da Medicina entre os pares e na comunidade internacional de médicos historiadores. O editorial do segundo número da Revista Brasileira de História da Medicina (1. trim. 1950) traz elogios de Luiz Faria, secretário-geral da Academia Brasileira de História das Ciências, e de uma pessoa de muito prestígio no campo, Henry Ernest Sigerist (7.4.1891-17.3.1957), que fundara em 1933 o Bulletin of the Institute of the History of Medicine (atual Bulletin of the History of Medicine). Nascido em Paris, Sigerist doutourou-se na Universidade de Zurique em 1917 e, depois de servir como médico no exército suíço, passou a se dedicar à história de sua 'arte', primeiro nas universidade de Zurique e Leipzig e, a partir de 1931, na Johns Hopkins University School of Medicine. Em 1932 sucedeu William H. Welch na direção do Institute of the History of Medicine, na qual permaneceu até 1947. Dedicou-se à escrita de uma história da medicina que teria oito volumes, dos quais foi publicado apenas o primeiro até sua morte, em 1957. Além de ter sido um pioneiro no estudo da história social da medicina, Sigerist foi personagem de grande influência no movimento pela implementação de uma medicina socializada. Para Sigerist, o programa da revista era interessante e abrangente e traria contribuições expressivas tanto para o avanço da medicina quanto para o estudo da sua história. ${ }^{5}$

Outro personagem a saudar a Revista Brasileira de História da Medicina foi o médico Carlos Enrique Paz Soldan, catedrático da Universidade de Lima e fundador da Sociedade Peruana de História da Medicina. A edição de 1950 da revista traz exortações de outros estudiosos da história da medicina: Félix Martí Ibánez, que se tornou membro correspondente do Instituto Brasileiro de História da Medicina; Karl Reucker, vice-diretor da Ciba S.A. Basiléia e redator da Ciba Zeitschrift, eleito membro honorário do Instituto; Figueiredo Baena, catedrático de urologia da Faculdade Nacional de Medicina da Universidade do Brasil; Erich Gruen, doutor em medicina pelas Universidades de Berlim e Roma e ex-assistente de história da Universidade de Roma, na cátedra regida por Adalberto Pazzini.

O intercâmbio dos médicos historiadores brasileiros com instituições estrangeiras, sobretudo as européias e, muito especialmente, as de Portugal e Espanha, inclui o seu engajamento em eventos internacionais. Trinta países, inclusive o Brasil, enviaram delegações oficiais ao $15^{\circ}$ Congresso Internacional de História da Medicina ${ }^{6}$, realizado em Madri, em setembro de 1956. Promovido pela Sociedade Internacional de História da Medicina, teve como presidente Pedro Lain Entralgo (1908-2001), verdadeiro patriarca da disciplina na Espanha, onde, graças à sua influência, hoje está disseminada e muito ativa no âmbito das faculdades de medicina. Médico, professor e escritor espanhol, Entralgo fez seus estudos em química, medi- 
cina e cirurgia em Zaragoza, Valência e Madri e aperfeiçoou-se em Viena. Foi diretor da revista Escorial e da Editora Nacional, professor de psicologia experimental, depois catedrático de história da medicina na Universal Central de Madrid (1931-1941), da qual foi reitor de 1952 a 1956 (Benito, s.d.).

$\mathrm{O} 16^{\circ}$ Congresso Internacional de História da Medicina teve lugar na Universidade de Montpellier, na França, entre 22 e 28 de setembro de 1958. O seguinte reuniu-se na Universidade de Atenas, Grécia, em setembro de 1960. O Instituto e a Federação brasileiras tiveram participação ativa na organização do $1^{\circ}$ Congresso Pan-americano de História da Medicina, realizado na cidade do Rio de Janeiro de 12 a 20 de abril de 1958. Na ocasião foi fundada a Academia Panamericana de História da Medicina, sendo eleito presidente, por aclamação, o incansável Ivolino de Vasconcellos. O 2º Congresso Pan-americano de História da Medicina e o $1^{\circ}$ Congresso Venezuelano de História da Medicina transcorreram simultaneamente em Caracas, Venezuela, em junho de 1961, sob a presidência de Franz Conde Jahn, da Sociedade Venezuelana de Cirurgia.

No mesmo período, as entidades brasileiras lideradas por Vasconcellos organizavam congressos nacionais. O $1^{\mathrm{o}}$ Congresso Brasileiro de História da Medicina foi realizado no Rio de Janeiro, em julho de 1951; o segundo ocorreu em Recife, em julho de 1953; o terceiro (e último em vida de Vasconcellos) teve lugar novamente na capital brasileira, em 1958, junto com o $1^{\circ}$ Congresso Pan-americano de História da Medicina. Comemorava-se então 150 anos da fundação do ensino médico no Brasil, e os temas oficiais dos congressos foram "A medicina pré-colombiana" e a "História do ensino médico no Brasil" (ago. 1957).

A Revista Brasileira de História da Medicina desempenhou importante papel na consolidação dessa rede de relações e na solidificação das bases de sustentação da Federação Nacional de História da Medicina e Ciências Afins.

A publicação reunia diversas seções. Os editoriais eram sempre assinados por Ivolino de Vasconcellos, presidente perpétuo da revista. Em geral, limitavam-se a relatar comemorações e prestar homenagens, fossem elas decorrentes da criação de institutos ligados à história da medicina ou da realização de eventos. De fato, a revista divulgava à comunidade médica brasileira os diversos congressos de história da medicina, dos quais o Instituto e a Federação participavam, informando o leitor sobre datas, locais e temas, além de relatar as cerimônias.

A seção intitulada Galeria da Federação punha em destaque figuras prestigiadas da comunidade médica nacional que participavam da Federação Nacional de História da Medicina e Ciências Afins. A seção mais nobre era a dos artigos originais, grande parte dos quais se limitava a prestar homenagens ou relatar a vida e obra de 
determinados personagens 'demiúrgicos' da medicina, geralmente já falecidos; tratava-se também nessa seção das atividades da Federação Nacional de História da Medicina. Do mesmo modo, eram freqüentes os artigos sobre a história da profissão médica com abordagem positivista, enaltecendo grandes personagens e acontecimentos que fizeram 'evoluir a arte', das superstições rumo à eficácia e cientificidade. Ivolino de Vasconcellos assinou cerca da metade do total desses artigos. Os demais foram escritos sobretudo por membros correspondentes, vitalícios ou honorários, das instituições às quais a revista servia de porta-voz, como Ordival Cassiano Gomes, Arthur Pinto da Rocha, Carlos Silva Araújo, Manuel Xavier de Vasconcelos Pedrosa, Roberval Bezerra de Menezes e Avertano Rocha, este presidente do Instituto Paraense de História da Medicina. ${ }^{7}$ Grande parte dos artigos provinha do estado da Guanabara, onde estava sediada a revista, mas houve contribuições importantes de autores estrangeiros como Ernest Wickersheimer, membro honorário do Instituto Brasileiro de História da Medicina, que publicou o artigo "Um médecin français au Brésil em 1821" (1. trim. de 1952) e o próprio Lain Entralgo, autor do artigo “Gregório Marañon, medico" (set.-out. 1960).

A seção História Pitoresca da Medicina era um repositório de feitos e fatos notáveis da medicina no passado. Um exemplo são as novidades terapêuticas do século XVII, tema de "Medicina seiscentista", escrito por Luiz Lamego (1. trim. 1950, p.129-133), um dos organizadores d'A Revista da Academia Fluminense de Letras em 1949. ${ }^{8}$ Resenhas de Livros e Publicações, outra seção corrente, acompanhava o movimento da literatura no campo da história da medicina. A seção Galeria Médica Universal retratava, de forma apologética, figuras das ciências médicas.

Os trabalhos recebidos para publicação eram avaliados pelo Conselho Redatorial, do qual participavam colaboradores do Rio de Janeiro, São Paulo, Bahia, Minas Gerais, Maranhão, Pernambuco, Rio Grande do Sul, Pará e Paraná. A revista tinha, também, um Conselho Científico Nacional, com nomes importantes da medicina clínica e experimental e da história da medicina, como Pedro Nava, autor, entre outros clássicos, de Território de epidauro (1947); Heráclides-Cezar de Souza Araújo, cientista do Instituto Oswaldo Cruz que publicou o ainda insuperado História da lepra no Brasil (1946, 1956), e Renato Clarck Bacellar, autor de Brazil's contribution to tropical medicine and malaria: personalities and institutions (1963).

A revista contava com colaboradores também na Suíça, Espanha, Argentina, Estados Unidos, Guatemala, Peru, México, Bélgica, França e Inglaterra. Esses médicos historiadores estrangeiros também avaliavam os originais submetidos à publicação.

A Comissão da Revista encarregava-se da rotina editorial. Os originais deviam ser datilografados em espaço duplo, com resumo em português e, se possível, em outras línguas vivas. Deviam ser acom- 
panhados pelo autógrafo do autor, em tinta preta e papel branco, pois na época o processo gráfico envolvia a confecção de clichê. A redação fornecia aos autores, gratuitamente, cinqüenta separatas dos artigos publicados. Caso fosse necessário um número extra de separatas, fazia-se um ajuste prévio. Era permitida a transcrição de trabalhos publicados pela revista, desde que indicada a fonte. As citações bibliográficas deviam seguir a norma do Index Medicus (autor, título, nome abreviado da publicação, volume, página, mês, se possível o dia, e ano).

É importante ressaltar a preocupação em padronizar a nomenclatura utilizada em citações e referências bibliográficas; uma das exigências era que o título do periódico fosse sempre citado da seguinte forma abreviada: Rev. Bras. Hist. Med. Entre as recomendações da editoria da revista a seus colaboradores incluíam-se aquelas relativas à documentação fotográfica e às considerações de ordem geral, que deveriam restringir-se ao "estritamente necessário".

A Revista Brasileira de História da Medicina tinha como assinantes indivíduos e instituições de ciência e cultura. Sabe-se que, em pouco tempo, o número de assinantes estrangeiros aumentou, sendo este um reflexo do interesse pelos estudos de história da medicina elaborados no Brasil.

O periódico também contava com anunciantes, em geral empresas de alimentos e remédios, sobressaindo entre elas Produtos Químicos Ciba S.A. e o Laboratório Gross, ambos do Rio de Janeiro; Laborterápica Bristol S.A. e Indústria Química e Farmacêutica Santo Amaro, de São Paulo; e Nestlé, que veiculava propaganda de Lactogeno. Também observam-se anúncios da Roche, Químicos e Farmacêuticos S.A. e da Indústria Química e Farmacêutica Schering S.A.

A Revista Brasileira de História da Medicina divulgava uma série de congressos e eventos internacionais que contribuíam com o intercâmbio entre os historiadores da medicina do Brasil e da Europa. Neste sentido, o trabalho desenvolvido pelos historiadores da medicina da época e o papel desempenhado pela revista foram fundamentais para desfazer a noção de que a ciência produzida no país, inclusive a ciência médica, simplesmente imitava e reproduzia os modelos europeus.

Nas investigações sobre o periódico foi possível observar que ele já trazia características adotadas por publicações especializadas nas diversas áreas de conhecimento, como a existência de conselho redatorial, que avaliava os originais submetidos à publicação, e normas para elaborar citações, abreviaturas, referências bibliográficas, tal como as revistas científicas produzidas hoje.

Como precursora na disseminação de artigos sobre a história da medicina em nosso país, a revista foi um incentivo à produção bibliográfica numa área de conhecimento pouco difundida, da qual faria parte, anos depois, História, Ciências, Saúde-Manguinhos, perió-dico editado pela Casa de Oswaldo Cruz/Fiocruz. ${ }^{9}$ 


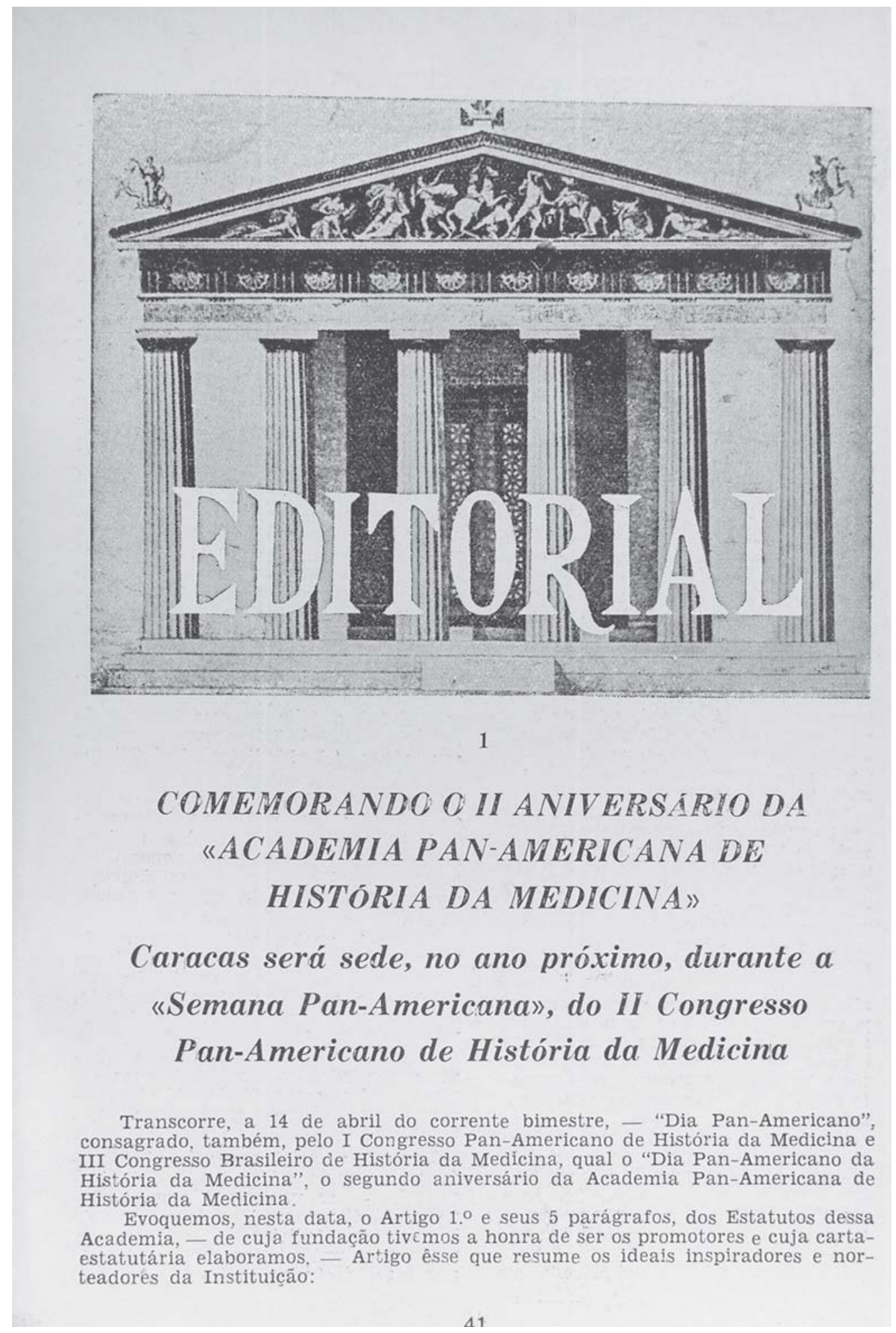

Figura 1: Folha de rosto da seção Editorial (n.2, v.11, mar.-abr. 1960). Acervo Biblioteca de Manguinhos/Fiocruz 


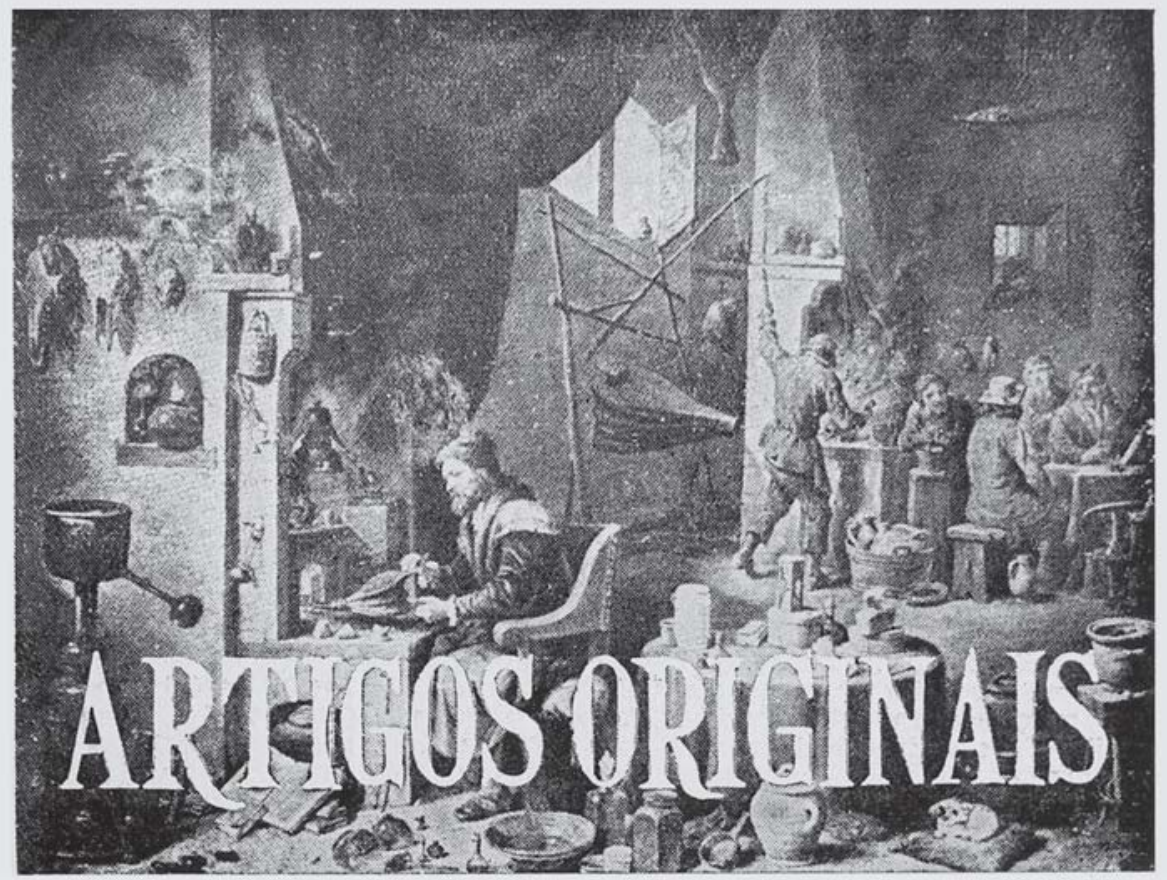

\section{ORACÃO DO XIV ANIVERSARIO DO INSTITUTO BRASILEIRO LE HISTÓRIA DA MEDICINA}

IVOLINO DE VASCONCELLOS

Presidente do Instituto Brasileiro da Federacão Nacional e da Academia Pan-Americana de História da Medicina. Delegado no Brasil da Sociedade Internacional de História da Medicina. Docente da Faculdade Nacional de Medicina da Universidade do Brasil

"Viver sem amigos não é viver", dizia Cícero, e posso compreender, devéras, o profundo significado do luminoso conceito, em instante qual o de agora. É que, em verdade, o que somos. e o que valemos, aos amigos, e somente aos amigos, devemos. .

Desejassemos definir êste instituto, e esta Federacão, e êste movimento de espiritos e de coracões, que em tômo da História da Medicina se c.evantou, faz, hoje, quatorze anos, e que desia Capital se irradiou, para todos os recantos do pais, a palavra "mizade" se- ria a singela explicação de tudo.. Amizade, que é o amor dos espíritos, a inclinacão comum dos anseios, a vocação no rumo dos mesmos ideais, a alianca das almas, a fracernidade cos coracões, a castalina fonte de tôdas as benésses humanas.

Transformou-se, esta Instituicão, numa grande mansão da amizacle, a unir, nas abençoadas seáras da Medicina, co'egas de todo o país, e fazendo-o pelos caminhos floridos do desinteresse, da abnegação, da generosidade e do patriotismo, em pról dos mais no-

Figura 2: Folha de rosto da seção Artigos Originais (n.2, v.11, mar.-abr. 1960) Acervo Biblioteca de Manguinhos/Fiocruz 


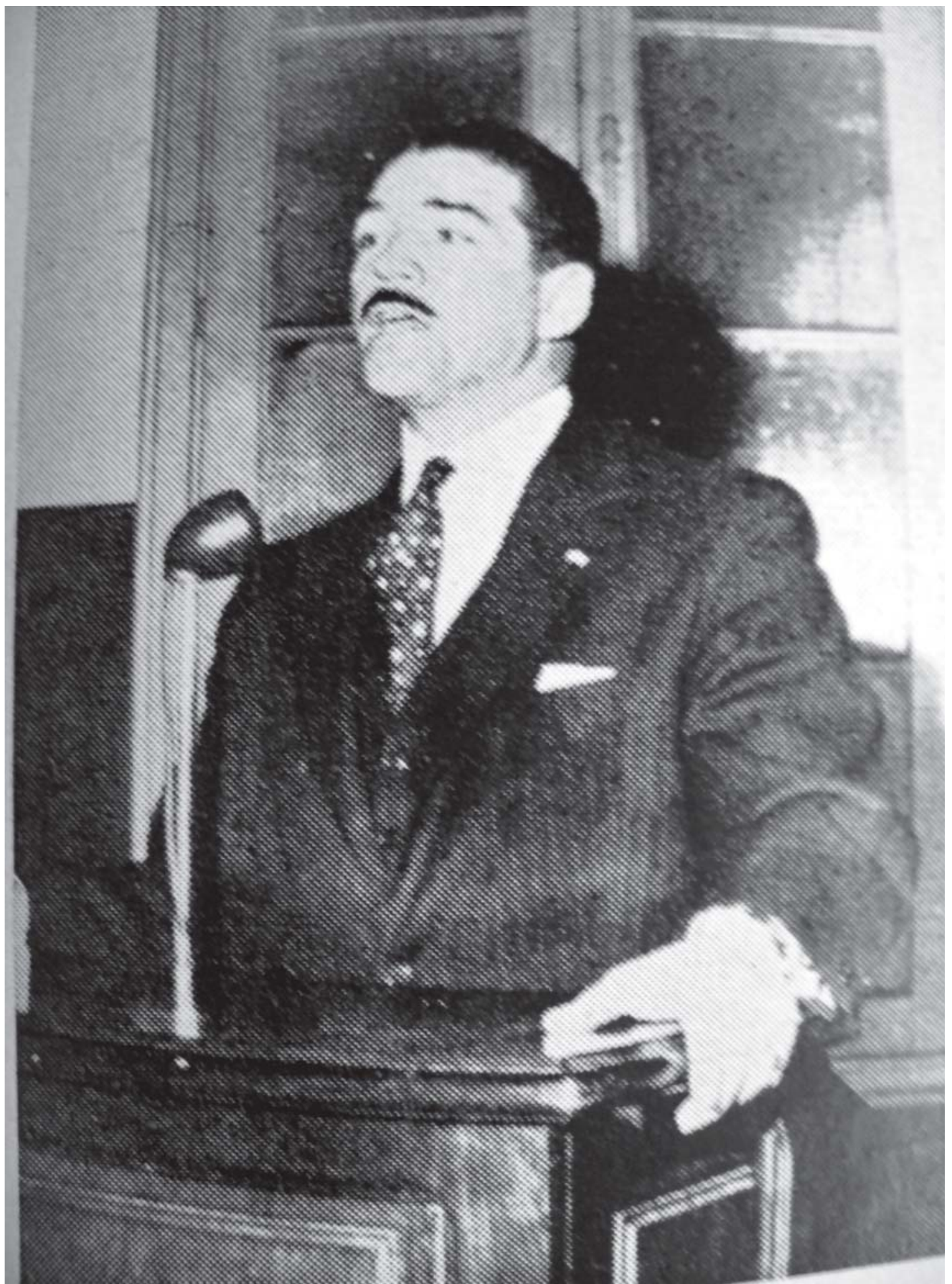

Figura 3: Ivolino de Vasconcellos discursando na seção científica do 17ํㅡㄹ Congresso Internacional de História da Medicina, realizado em setembro de 1960 na Universidade de Atenas (n.2, v.12, mar-abr. 1961). Acervo Biblioteca de Manguinhos/Fiocruz 


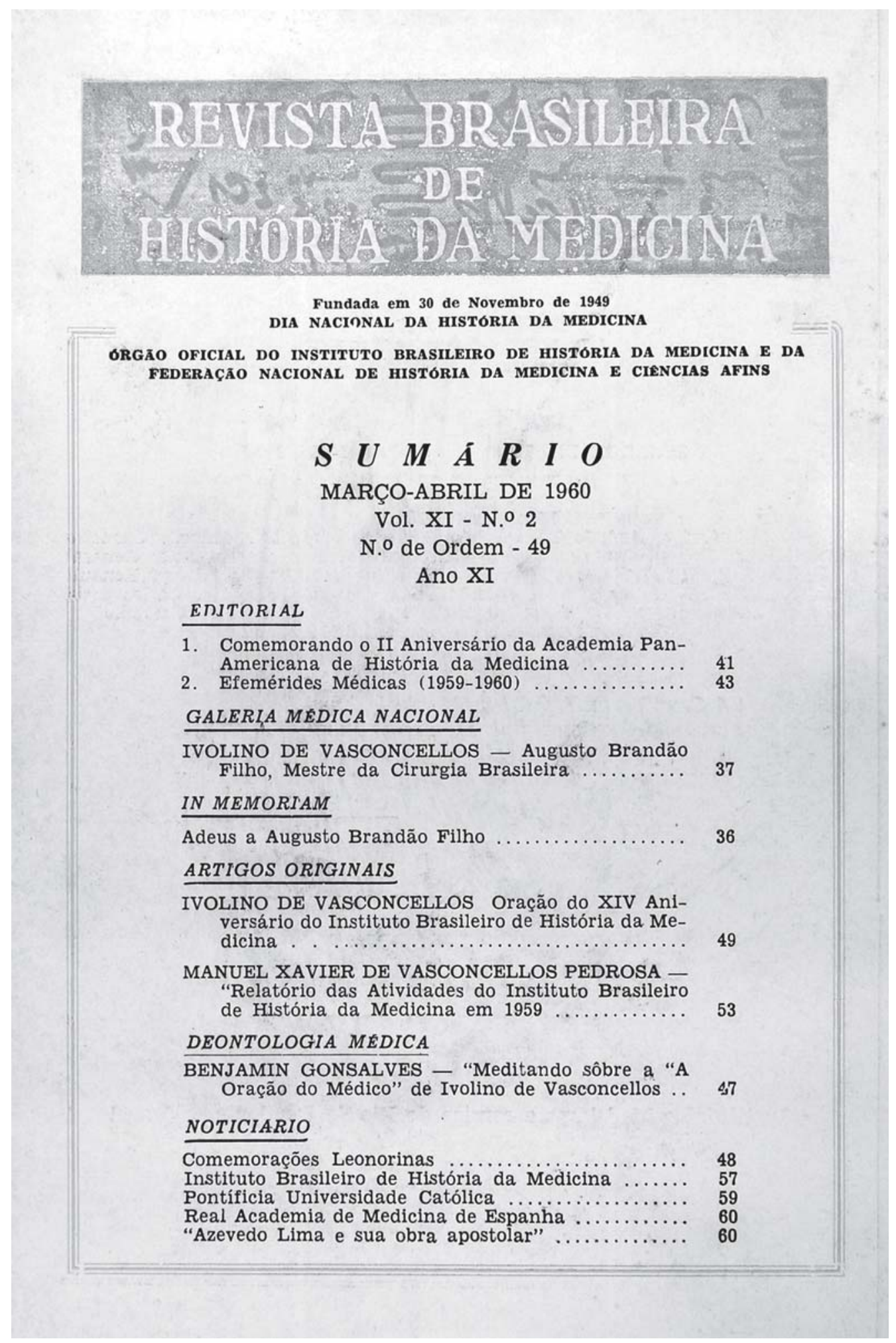

Figura 4: Sumário (n.2, v.11, mar.-abr. 1960). Acervo Biblioteca de Manguinhos/Fiocruz 


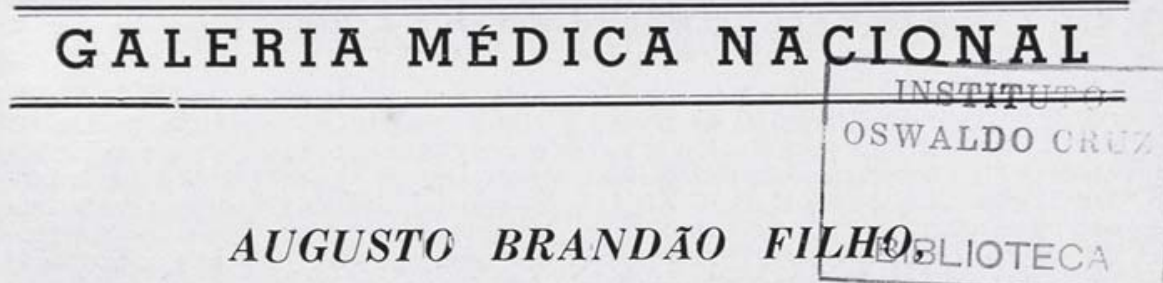

\section{MESTRE DA CIRURGIA BRASILEIRA}

IVOLINO DE VASCONCELLOS

Presidente Perpétuo do Instituto Brasileiro e da Federacão Nacional de História da Medicina e Ciências Afins - Presidente da Academia Pan-Americana de História da Medicina - Delegado no Brasil da Sociedade Internacional de História da Medicina - Docente da Faculdade Nacional de Medicina da Universidade do Brasil

Nasceu Augusto Brandão Filho em 19 de maio de 1881 , na cidade de Cantagalo, Estado do Rio de Janeiro, filho do Professor Augusto de Sousa Brandão, Catedrático de Clínica Ginecológica da Faculdade de Medicina do Rio de Janeiro e de D. Leocádia de Sousa Brandão.

Seus estudos de humanidades, fê-los no Colégio Alfredo Gomes, na Rua das Laranjeiras, e os preparatórios no Externato Aquino, à Rua da Constituição. A vocação para a Medicina, teve, no exemplo paterno, de grande médico e professor, o melhor e profícuo estímulo. Ser médico, assim como o pai. foi sempre o grande anseio do jovem.

É desta forma que se matricula, em 1896. na Faculdade de Medicina, onde principia, afanosa e entusiàsticamente, os labores estudantis do curso médico. Do seu devotamento ao estudo bem alto fala o fato de que, sem interrupção no currículo de Medicina, dedica-se, simultâneamente, ao curso farmacêutico, alcançando com brilho, êste último grau, dois anos depois, em 1900 .

Por êste tempo, - aluno sequioso de aprendizado prático, - principia a freqüentar o Hospital da Misericórdia, que se lhe vincularia, indissolùvelmente, à existência. É o tímido estudante, amanhecendo antes da turma, para as tarefas da Medicina militante, que surge, peios corredores do vetusto nosocômio, esgueirando-se, entre os alunos mais graduados, para ouvir liçōes magistrais ou acompanhar as práticas que tanto 0 seduzim. Eis que se lhe define, em breve, a vocacão especializada: a cirurgia. O jovem estudante elegera, em locais prediletos, as enfermarias cirúrgicas e as salas operatórias se lhe torna:ram fecunda obcessão.

Tão grande lhe era o afinco no estudar, tão intenso o esfôrç no aprender e tão firme a tenacidade no adestrar-se, que sua presença começou a ser notada pelos mestres. Ei-lo, em 1902, interno da Clínica Cirúrgica, sob a direcão do Professor João dả Costa Lima e Castro, em cujos ensinamentos sentiu desenvolverem-se-lhe a devoção aos enfermos e o amor à cirurgia.

Bem compreendia, entretanto, o jo$v \in m$ doutorando, que o cirurgião, verazmente digno dêsse nome, deve conhecer, profundamente, a clínica. E foi, igualmente interno de Clínica Médica, em 1903, servindo ao consagrado Professor Benício de Abreu, de quem se fêz auxi.iar dos mais solicitos e eficientes, e com quem aprendeu os segredos fundamentais da arte clínica.

É nesse mesmo ano que se forma em Medicina, defendendo, com ilustracão tese inaugural sob o título "Hérnia perineal posterior", em que consubstancia o eficiente aprendizado clínico-cirúrgico, ao mesmó tempo que define a marcada predileção para as artes operatórias.

Ei-lo a seguir, por proposta do saudoso Dr. Daniel de Almeida, nomeado.

Figura 5: Folha de rosto da seção Galeria Médica (n.2, v.11, mar.-abr. 1960)

Acervo Biblioteca de Manguinhos/Fiocruz 

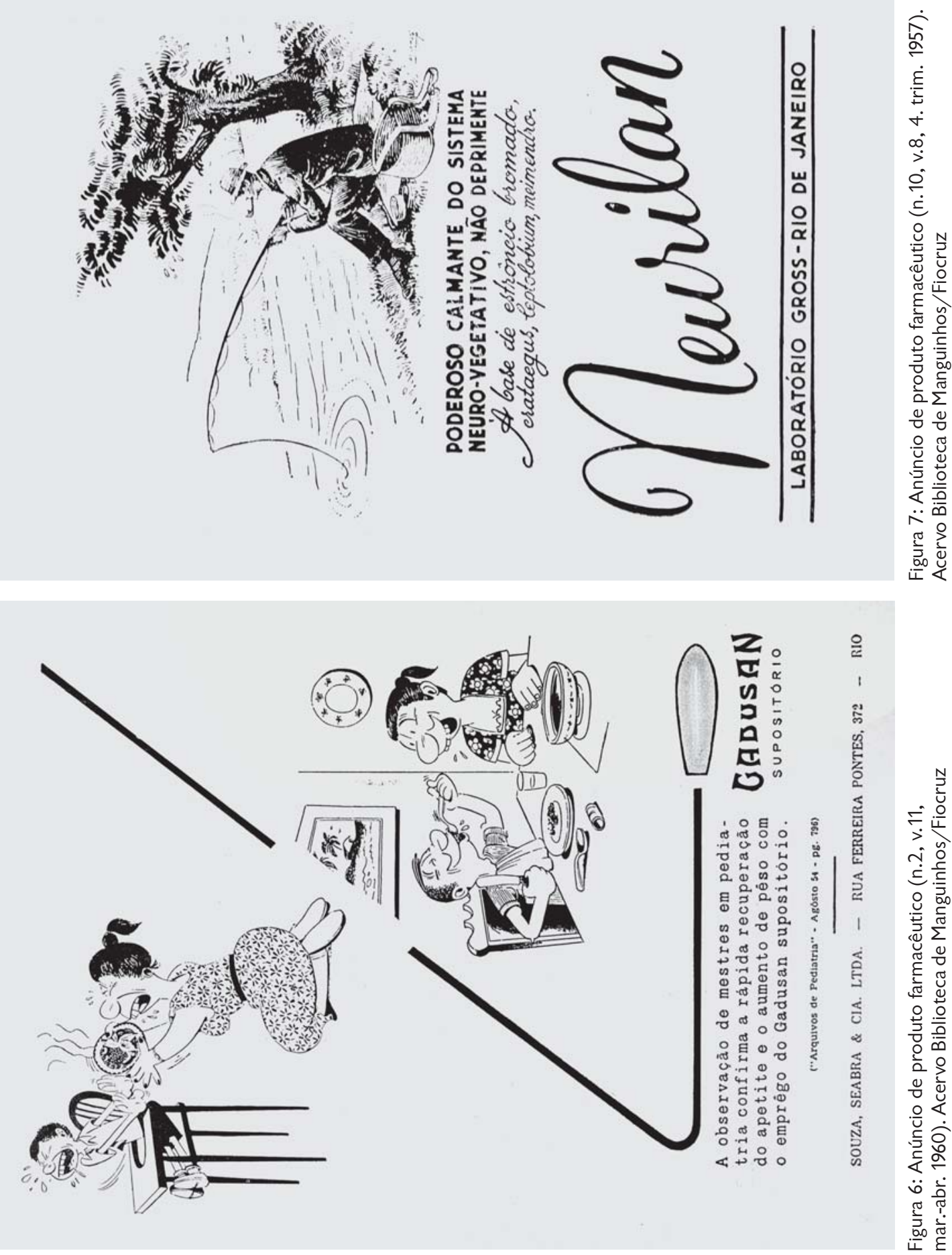

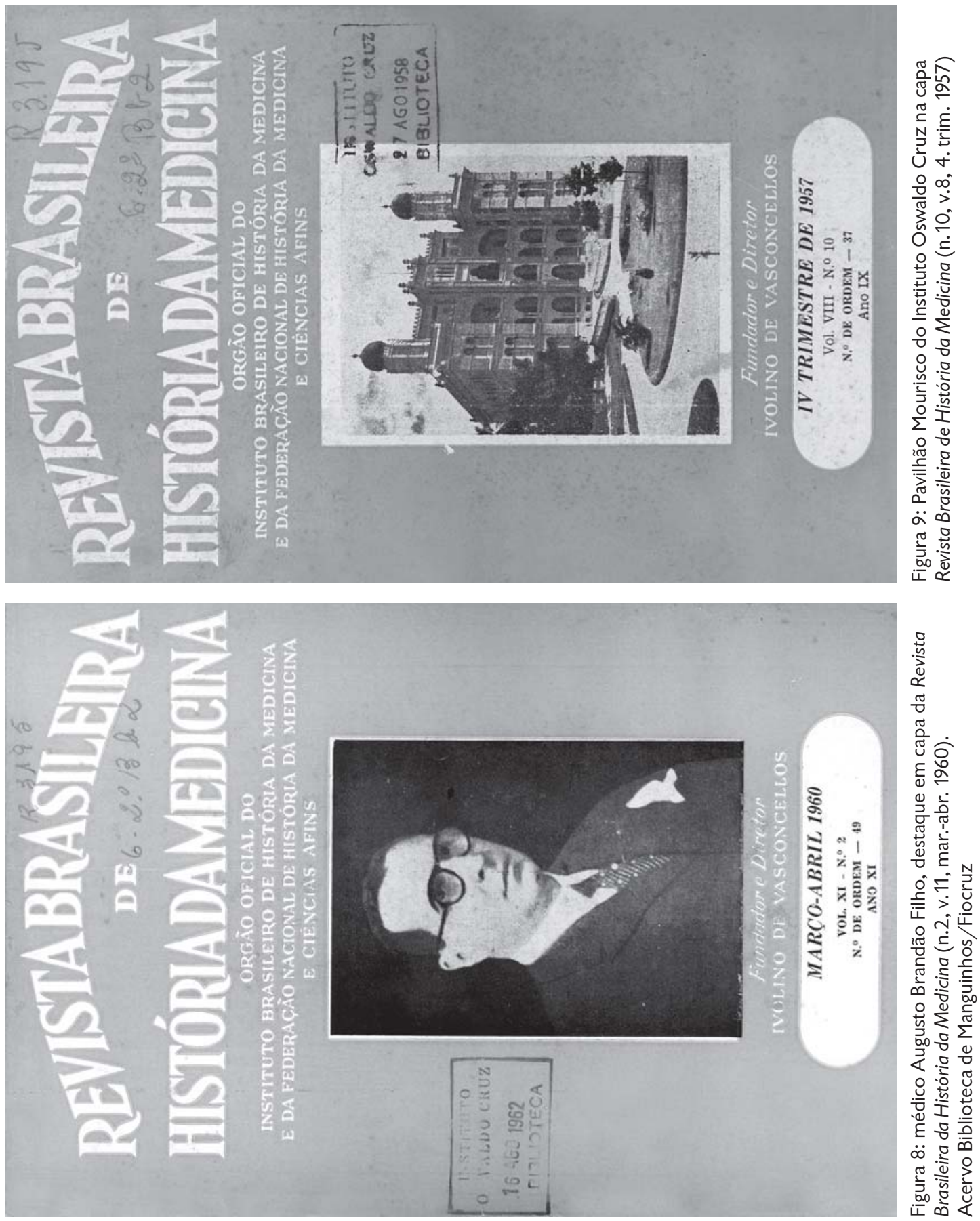


\section{NOTAS}

${ }^{1}$ Relatório final apresentado pelo bolsista Gabriel Baptista Nicolini na jornada de iniciação científica da Fundação Oswaldo Cruz, em abril de 2004.

2 Não foi possível saber onde eram sediadas as duas entidades. Provavelmente nos mesmos endereços da Revista Brasileira de História da Medicina, cuja redação funcionava na rua México n.164, segundo andar, no centro da cidade do Rio de Janeiro, e administração na rua Antônio Vieira n.28, no bairro do Leme

${ }^{3}$ Coube ao professor da Faculdade de Medicina da Paraíba, Lorival Moura, pôr em prática o projeto concebido por Ivolino de Vasconcellos, de criação do instituto de história da medicina naquele estado.

${ }^{4}$ A primeira diretoria dessa entidade, ainda como seção da Sociedade de Medicina de Porto Alegre, foi presidida por Martim Gomes e teve como secretários Pascoal Adrio Crocco e Erwino Diefenthaeler. A diretoria seguinte (1949), presidida por João Gomes da Silveira, era constituída por João Gomes da Silveira (presidente); Coradino Lupi Duarte (vice-presidente); Tasso Vieira de Faria (secretário-geral), Pedro Luiz Costa e Fradique Correa Gomes (1ํㅜ e $2^{\underline{0}}$ secretários); Ana Maria Sparvoli (tesoureira), Lauro Schuck (bibliotecário) e Erwino Diefenthaeler (diretor do órgão). Ao estudar a "Psicologia nas Teses da Faculdade de Medicina de Porto Alegre", Cristina Lhullier e Marina Massim refere-se à investigação que Tasso Vieira de Faria desenvolveu em 1949, junto à disciplina de clínica ginecológica, sobre a sexualidade feminina. Utilizava um teste projetivo, o teste de Rorschach, como instrumento diagnóstico para estabelecer um conhecimento mais aprofundado da personalidade de suas pacientes (Lhullier, Massimi, 2006).

5 Sobre Henry Ernest Sigerist, ver Nunes (1992).

${ }^{6}$ Ivolino de Vasconcellos participou desse evento como delegado oficial do Brasil.

${ }^{7}$ Quando se associavam ao Instituto, os indivíduos estabeleciam um vínculo com o periódico e passavam a ser considerados seus membros, nas categorias correspondente, vitalício e honorário, entre outras.

8 "Durante a direção de Lamego e de Lacerda Nogueira, que compreende as décadas de 1950 e 1960, a Revista [da Academia Fluminense de Letras] teve periodicidade anual e tornou-se o repositório da história dessa agremiação, pois publicou trabalhos de acadêmicos - artigos, poemas, estudos, conferências e discursos." (Fernandes, 2006, p.4).

${ }^{9}$ Ver neste mesmo número o artigo História, Ciências, Saúde - Manguinhos: um balanço de 12 anos de circulação ininterrupta.

\section{BIBLIOGRAFIA}

Alfonso-Goldfaber, $\quad$ O que é história da ciência.

Amaral, Afrânio do

Siphilis - moléstia e termo-através da história.

Amoroso, Mauro

H. de Barros

[s.d.]

Bacellar, Renato Clarck 1963

Rio de Janeiro: Instituto Nacional do Livro.

A importância de Ivolino de Vasconcellos e do IBHM na consolidação da historiografia médica brasileira. Revista Cantareira, Niterói, 6. ed. online. Disponível em: http://www.historia.uff.br/cantareira. Acesso em 20 fev. 2007. Brazil's contribution to tropical medicine and malaria: personalities and institutions. Rio de Janeiro: Gráfica Olimpica.

Benchimol, Jaime;

Martins, Ruth B.

2004

Benito, Enrique Pérez

Fernandes, Rui A. Nascimento

História, Ciências, Saúde-Manguinhos: una revista en la frontera de las ciencias sociales y de las ciencias de la vida. Boletín Mexicano de Historia y Filosofia de la Medicina, Ciudad de México, v.7, n.1-2, p.53-59.

Pedro Laín Entralgo. Disponível em: http://www.catedramdelibes.com/ archivos/000060.html. Acesso em: 5 mar. 2007.

Curso de Estudos Fluminenses: o lugar da história na configuração de um campo de reflexão intelectual sobre o estado do Rio de Janeiro, na década de 1950. In: Seminário de História: caminhos da historiografia brasileira contemporânea, 1., 2006, Ouro Preto. Anais... Disponível em: http://www.ichs.ufop.br/seminariodehistoria/download/I-seminariohistoria-ichs-ufop(2006)-n58.pdf. Acesso em: 2 mar. 2007. 
Gomes, Ordival

Cassiano

1974

Gomes, Ordival Cassiano

1957

Gomes, Ordival Cassiano 1953

Gomes, Ordival

Cassiano

1949

The Henry.. 2007

Lamego, Luiz

1. trim. 1950

Lhullier, Cristiana;

Massimi, Marina

2007

Nava, Pedro

1947

Nunes, Everardo

Duarte

1992

Oliveira, Eduardo de Sá 1992

RBHM

Souza Araújo,

Heráclides-Cesar

1956

Souza Araújo,

Heráclides-Cezar

1946

Vasconcellos, Ivolino de 1964

Vaz, Eduardo nov. 1950
História da medicina no Brasil no século XVI. Rio de Janeiro: Instituto Brasileiro de História da Medicina.

Manuel Victorino Pereira: médico e cirurgião.

Rio de Janeiro: Agir.

A medicina no século XVII. As descobertas científicas. Os iatrofísicos e os iatroquímicos. Thomas Sydenham e o neo-hipocratismo seiscentista. Revista de história, São Paulo, ano 4, v.13.

Pai de Rui, dr. João José Barbosa de Oliveira. Rio de Janeiro: Casa de Rui Barbosa, 1949.

The Henry E. Sigerist Collection. In: Repository Guide to the Personal Papers Collections of Alan Mason Chesney Medical Archives. Baltimore: Johns Hopkins Medical Institutions. Disponível em: http:// www.medicalarchives.jhmi.edu/sgml/sigerist.html. Acesso em: 5 mar.

A medicina seiscentista. Revista Brasileira de História da Medicina.

Rio de Janeiro, v.1, n.2, p.129-133.

Psicologia nas teses da Faculdade de Medicina de Porto Alegre.

In: Gomes, William Barbosa (Org.). Psicologia no estado do Rio Grande do Sul. Porto Alegre: Museu Virtual da Psicologia. Disponível em: http:// www.ufrgs.br/museupsi/PSI-RS/Chap2.htm. Acesso em: 2 mar.

Território de epidauro.

Rio de Janeiro: C. Mendes Junior, 1947.

Henry Ernest Sigerist: pioneiro da história social da medicina e da sociologia médica. Educación Médica y Salud, Washington, v.26, n.1, p.70-81.

Memória histórica da Faculdade de Medicina da Bahia: concernenente ao ano de 1942. Salvador: Centro Editorial e Didático da UFBA.

Revista Brasileira de História da Medicina. Rio de Janeiro: Instituto Brasileiro de História da Medicina, Federação Nacional de História da Medicina, 1949-1963, 1969-1970. Periodicidade diversa.

História da lepra no Brasil: período republicano (1890-1952).

Rio de Janeiro: Imprensa Nacional.

História da lepra no Brasil: períodos colonial e monárquico (1500-1889).

Rio de Janeiro: Imprensa Nacional.

Asclépio historiador. Rio de Janeiro: Instituto Brasileiro de História da Medicina, Federação Nacional de História da Medicina e Ciências Afins.

Vital Brazil. Anais Paulistas de Medicina e Cirurgia, São Paulo, v.60, n.5, p.347366. Conferência realizada na Escola Paulista de História da Medicina.

Recebido para publicação em setembro de 2006.

Aprovado para publicação em janeiro de 2007. 